\title{
A crise afetiva e identitária do médico psiquiatra em Memória de elefante, de António Lobo Antunes
}

\section{The affective and identity crisis of the psychiatric doctor in Memory of Elephant, by António Lobo Antunes}

\author{
Suzana Costa da Silva ${ }^{1}$
}

"Na noite mais escura da alma são sempre três horas da manhã."

(Scott Fitzgerald)

\section{Resumo}

A descrição de um dia inteiro do personagem "médico psiquiatra" do romance Memória de elefante (1979), de António Lobo Antunes, é realizada pelas próprias lembranças do passado em meio aos acontecimentos atuais. A vida degradante e depressiva, que se instaura após sua estada em África como médico, será uma marca desse indivíduo à deriva, que, fragmentado, não restabelece sua identidade perdida. Em crise, vive os dramas da separação da mulher e o distanciamento das filhas e busca, nas pequenas ações do cotidiano, as evasões para o seu desamparo. Sem interação social e pessoal, vive o desencanto solitário da frustração de uma realidade insignificante, somados a um nível depressivo que o mantém inerte em suas decisões. A angústia, o sofrimento amoroso e a profunda crise de identidade permeiam a narrativa, tornando líquidas a sensibilidade e a dignidade desse homem, marcas de uma escrita envergada à ótica da pós-modernidade em que o autor desafia o público a decodificar as vozes que soam nesse discurso, representando o seu rigor comunicativo. António Lobo Antunes fornece já no primeiro romance de sua vida, uma escrita psicológica e quase autobiográfica, quando muitas informações ficcionais se confundem com a realidade vivenciada pelo autor. Maria Alzira Seixo, Ana Paula Arnaut, Stuart Hall, Zygmunt Bauman entre outros teóricos serão utilizados para promover discussões sobre a escrita e a crise do sujeito em seu tempo e espaço. O Pierrot de um mundo pósmoderno ainda está aprisionado ao passado, um tempo que não será recuperado, a não ser pelas memórias do que poderia ter sido e não foi.

Palavras-chave: Identidade. Memória. Fragmentação. Pós-moderno. Passado.

\begin{abstract}
A full day description of a "psychiatric" character from the novel Memory of Elephant, by António Lobo Antunes, is made by his memories amid the current events. The degrading and depressive life, which establishes itself after his stay in Africa as a doctor, will be the mark of this individual adrift, who, fragmented, does not restore his lost identity. In a crisis, he lives the drama of his divorce from his wife and the distance of his daughters, and searches for, in the small actions of daily
\end{abstract}

\footnotetext{
${ }^{1}$ Doutorado em Literatura Portuguesa pela Universidade do Estado do Rio de Janeiro (UERJ), Rio de Janeiro, Rio de Janeiro, Brasil.E-mail: suzana_cs18@yahoo.com.br
} 
life, the evasions for his helplessness. Without social and personal interaction, he lives the lonely disenchantment of the frustration of an insignificant reality, added to a depressive level that keeps him inert in his decisions. The anguish, the loving suffering, and the deep identity crisis permeate the narrative and become the sensibility and dignity of this man fluid, marks of a writing curved to the post-modernity optics, in which the author challenges the public to decode the voices that sound in this discourse, representing its communicative accuracy. António Lobo Antunes provides, in the first novel of his life, a psychological and almost autobiographical writing, when numerous fictional information is confused with the reality experienced by the author. Maria Alzira Seixo, Ana Paula Arnaut, Stuart Hall, Zygmunt Bauman, and other theorists will be used to promote discussions about the writing and the crisis of the subject in his time and location. The Pierrot of a postmodern world still is imprisoned to the past, a time that will not be recovered, unless by the memories of what could have been and was not.

Keywords: Identity. Memory. Fragmentation. Postmodern. Past.

António Lobo Antunes, autor contemporâneo, nascido em 1942, conheceu de perto as mazelas da guerra colonial como alferes médico do governo português. Conhecido por sua vasta produção literária, cujas memórias e recordações de Angola permanecem em muitas de suas obras, é autor de romances como: Explicação dos pássaros (1981), Fado Alexandrino (1983), Auto dos danados (1985), As Naus (1988), Manual dos Inquisidores (1996), Exortação aos Crocodilos (1999), O Meu Nome é Legião (2007), Não É Meia Noite Quem Quer (2012), Até Que as Pedras Se Tornem Mais Leves Que a Água (2017), A Outra Margem do Mar (2019), e um dos mais recentes, Diccionario da Linguagem das Flores (2020).

Junto com Memória de elefante (1979), objeto desta análise, Os cus de Judas, também de 1979 e Conhecimento do inferno, de 1980, formam a chamada "Trilogia de guerra", conceito estabelecido pela professora Ana Paula Arnaut para determinar a primeira fase do escritor denominada Autobiográfica ou de Aprendizagem.

Diante de toda complexidade de sua narrativa, Lobo Antunes estabelece com a escrita de seus romances uma relação de alteridade, confessando que "Talvez esteja grato a Angola porque foi lá que aprendi a existência dos outros [...] Nesse momento percebi que eu não era o centro do mundo" (ANTUNES apud ARNAUT, 2008, p. 428). Evoca em seus textos lembranças, relatos, vivências que somente quem presenciou de perto os horrores da guerra seria capaz de transmitir com tanta verdade. Memória de elefante é o primeiro romance de Lobo Antunes e apresenta uma narrativa densa, de um médico psiquiatra que vivenciou de 1971 a 1973, no exercício de sua função, a Guerra Colonial em África, guardando consigo as lembranças e as recordações do terror em que presenciou fora de seu país. Com marcas nitidamente autobiográficas, o romance aborda questões particulares da vida de um homem que, no retorno a sua pátria, vêse perdido na relação com as pessoas, cheios de traumas de guerra e que precisa aceitar a separação da esposa, com a qual tem duas filhas.

O romance é determinado em três partes: Manhã, Tarde e Noite, composto de cinco capítulos para cada parte, em que transcorre um dia da vida do médico, com todo seu esvaziamento, angústia e solidão. Através do viés afetivo e identitário do personagem principal, Antunes nutre-o com resquícios de uma profunda insatisfação e frustração, fatos que irão definir como esse indivíduo se porta diante da crise fragmentária a que condiciona o homem pós-moderno.

O médico-psiquiatra do romance analisado não possui nome na trama, que é a marca primária da ausência de uma identidade, e passa a maior parte do seu tempo no Hospital Miguel Bombarda, mesmo lugar que acompanhara o pai, também médico, durante a infância. No decorrer do seu dia põe-se a recordar a vida em África e os fatos vividos em família, com a mulher e as filhas. 
$\mathrm{O}$ enredo se desenvolve à medida em que as horas passam e o médico percebe sua insatisfação diante da vida. Extremamente introspectivo, o romance Memória de elefante narra, durante vinte e quatro horas, a rotina do psiquiatra mergulhado em uma profunda escuridão em que se encontra sua vida. A memória se mistura aos fatos reais, sobrepondo-se uns aos outros, transformando sua existência em uma obra de arte surrealista, onde o ideal onírico paira sobre a superfície da realidade, desestruturando a própria lógica dos acontecimentos. Ao assimilar os fatos de sua vida, aos poucos, o médico constrói um universo paralelo em sua mente e o objeto central de seus delírios passa a ser sempre o próprio sofrimento.

Dotado de uma profunda carga depressiva, o personagem confessa sua tristeza a uma enfermeira que estima "Estou a tocar no fundo" e acrescenta "oito mil metros de profundidade oceânica da tristeza, negrume de águas gelatinosas sem vida salvo um ou outro repugnante monstro sublunar de antenas, e tudo isto sem batiscafo, sem escafandro, sem oxigénio, o que significa, obviamente, que agonizo" (ANTUNES, 2009, p. 24-5). Neste trecho, sua vida pode ser claramente comparada a um quadro de Salvador Dalí.

O médico, apesar de fervilhar desespero, angústia e frustração interior, permanece inexorável perante essa realidade. Torna-se um sujeito desmotivado, indefeso e frustrado. A resposta que encontra é a única possibilidade que o conforta: "Talvez que eu esteja morto, pensou, certamente que morri de modo que nada de importante me pode já acontecer" (ANTUNES, 2009, p. 71).

Algumas marcas da fugacidade diante desse desespero incontrolável são as inúmeras atividades durante o dia, a fim de abster-se da realidade palpável e os choros constantes. Sofre ao retornar à casa vazia, em seu íntimo teme se ver sozinho, apesar de o estar todo o tempo. Por este motivo visita constantemente bares e locais públicos, fugindo do vazio que já é o próprio ser. Além de manter um "calendário de parede petrificado num março antiquíssimo, quando morava ainda com a mulher e as filhas" (ANTUNES, 2009, p. 43).
A crise existencial o degrada aos poucos e se manifesta na inconstância ao lidar com as pessoas, na dependência que ainda possui com a ex-mulher, na fixação pelas filhas, nos deslocamentos quase sempre cheios de lembranças e na incapacidade, que julga ter, de ser tornar um escritor. Esse ser fragmentado carrega "os ossos estilhaçados de seu desespero" (ANTUNES, 2009, p. 127). Perde toda sua força e fica à mercê da angústia que o assola e seus projetos de vida vão à contramão da ideia de vida que imaginava para si. "Tinha força: tinha mulher, tinha filhas, o projecto de escrever, coisas concretas, bóias de me aguentar à superfície" (ANTUNES, 2009, p. 62). Põe a família e seus projetos como atributos para alcançar a felicidade plena, mas com a perda desse ideal, não admite viver na decepção e no saldo negativo com a vida: "perdi gana de lutar, os braços não se movem, a voz na fala, os tendões do pescoço não seguram a cabeça" (ANTUNES, 2009, p. 62).

Sobre essa condição de ser fragmentado e deslocado de si mesmo, o sociólogo Zygmunt Bauman afirma em seu livro "Identidade": "Estar total ou parcialmente 'deslocado' em toda parte, não estar totalmente em lugar nenhum pode ser uma experiência desconfortável, por vezes, perturbadora. Sempre há coisa a explicar, desculpar, esconder ou, pelo contrário, corajosamente ostentar, negociar, oferecer, barganhar" (BAUMAN, 2005, p. 19).

E o médico está sempre disposto a justificar para si o motivo de sua condição, procurando na análise em grupo as respostas de que precisa, sabendo que poderá encontrá-las ou não, mas que a busca se faz necessária:

Há alturas em que estou fora daqui e penso em vocês e sinto a vossa falta, e depois perguntome o que representam para mim e não sei a resposta porque continuo sem saber a maior parte das respostas e tropeço de pergunta em pergunta como o Galileu antes de descobrir que a Terra se mexia e encontrar nessa explicação a chave das suas interrogativas (ANTUNES, 2009, p. 115).

Os diversos deslocamentos pela cidade ao longo do dia representam a fuga de si mesmo e 
dos pensamentos contínuos, marcas do homem moderno, pois para o sociólogo Zygmunt Bauman, em sua obra $O$ mal estar da pós-modernidade, "a modernidade é a impossibilidade de permanecer fixo. Ser moderno significa estar em movimento" (BAUMAN, 1998, p. 92). O deslocamento não é encontrado somente na deambulação do sujeito, mas também na estrutura da narrativa, ora em terceira pessoa (através do narrador) ora em primeira pessoa (apresentada pelos pensamentos e falas do protagonista). A alteração de tempos da narrativa também assume uma representação muito forte na escrita antuniana, do mesmo modo em que perpassam os narradores, os tempos entrecruzamse ligando o passado ao presente em apenas um fragmento de memória.

O choro no escuro do carro e os desabafos que faz no seu quarto ao fim do romance "podes me achar idiota mas preciso de qualquer coisa que me ajude a existir" (ANTUNES, 2009, p. 158) é o modo mais prático que encontra de barganhar com a vida uma forma mais simples de se viver. A angústia que toma conta do personagem de Memória de elefante perpassa a pele e é exteriorizada sem culpa, tamanha desilusão desse amor. Ele define seu sentimento como "angústia sem amarras da solidão absoluta" (ANTUNES, 2009, p. 28). Fadado a vivenciar essa profunda frustração, levando-o a uma profunda carga depressiva.

O tema da solidão é recorrente na trama de Antunes e aparece em diversas situações marcadas pelo desamparo e abandono, como mencionado em vários momentos pelo próprio protagonista. O médico, com saudades da mulher, enfatiza o seu eu vazio em trechos como "sentia-me muito indefeso e muito só" (ANTUNES, 2009, p. 123), ou mesmo a pensar que "jantar sem companhia o faria sentir-se ainda mais só" (ANTUNES, 2009, p. 126) e "diante do sofrimento, da angústia e da insônia" como forma de cura põe-se "a imaginar o mar" (ANTUNES, 2009, p. 79). O mesmo mar que para os portugueses sempre foi o ponto de apoio, a extensão das suas terras, uma zona de conforto necessária para os momentos de crise. Imaginar o mar seria a fuga das obsessões, o maior desejo de libertação. Para Maria Alzira Seixo, "O apelo das águas do mar, decorrente de vicissitudes infelizes, associa-se a obsessões que perseguem várias personagens: face à pulsão de morte que domina o espaço da guerra em África" (SEIXO, 2008 , p. 358, v. II). O mar, em um contexto póscolonial, representaria a possibilidade de regresso à terra natal, um retorno à casa ou a si mesmo. Essa aprendizagem de ida e retorno de uma guerra, para Lobo Antunes, representou

a sensação de não pertencerem nem cá nem lá, de se terem perdido naquele lugar e de não terem ainda conquistado lugar nenhum. Foi uma aprendizagem extremamente penosa, a do regresso e a sensação de ter de recomeçar tudo, de início. Era quase como ter que voltar a nascer, mas um voltar a nascer cheio de cicatrizes e cheio de feridas, extremamente doloroso, mas que eu penso que, agora, passados tantos anos, foi importante, quanto mais não seja para que a gente possa lutar para que uma situação dessas não volte a acontecer (ANTUNES apud ARNAUT, 2008, p. 26).

O sofrimento toma o protagonista pelas perdas e se estrutura em um relacionamento, que se rompe, mas que ainda continua inevitavelmente vivo dentro de si, em uma visão romantizada do que poderia ter sido eterno e não foi. Para essa visão, Bauman se mostra categórico: "No amor não há ajustes imediatos, soluções eternas, garantia de satisfação plena e vitalícia, ou de devolução do dinheiro no caso de a plena satisfação não ser instantânea ou genuína” (BAUMAN, 2005, p. 70). Por depositar expectativas no outro ser, o médico perdeu-se.

Com um egoísmo declarado, o protagonista jamais ofereceu ao outro o que lhe foi dado. Muito faltou a ser dito na relação conjugal. Nesta vida de sucessivos fracassos íntimos e pessoais, o homem refaz suas memórias pautadas em todo sofrimento vivido em África e depois dela. E, principalmente no arrependimento de não ter retribuído tudo o que recebeu: E eu, perguntou-se, que fiz eu verdadeiramente por ti, em que tentei, de facto, ajudar-te? Contrapondo o meu egoísmo ao teu 
amor, o meu desinteresse ao teu interesse, a minha desistência ao teu combate? (ANTUNES, 2009, p. 64).

Segundo Bauman em sua obra Amor líquido, no amor, o esforço e a dedicação são necessários para o sucesso. A troca é um balanceamento importante no relacionamento, não se deve apenas só receber ou só oferecer, é preciso um acordo entre as partes, para que nenhuma delas utilize-se da acomodação para fugir dos problemas. Ratificando essa conclusão, Bauman esclarece: "Sem humildade e coragem não há amor. Essas duas qualidades são exigidas, em escalas enormes e contínuas, quando se ingressa numa terra inexplorada e não mapeada. E é a esse território que o amor conduz ao se instalar entre dois ou mais seres humanos" (BAUMAN, 2004, p. 22).

O médico, em seus pensamentos constantes assume que:

[...] transformara a vida em um cenário de plástico, imitação esquemática de uma realidade por demais complexa e exigente para a minha reduzida panóplia de sentimentos disponíveis. E assim, insignificante pierrot de um carnaval frustrado, me consumia rapidamente numa labaredazinha portátil de angústia (ANTUNES, 2009, p. 140).

Para o escritor e artista plástico modernista Almada (1993), a figura do Pierrot é marcada pelo seu desejo incontrolável a um único amor, ele representa o interior humano, a tragédia, a inspiração, ao contrário de seu companheiro de cena, o Arlequim, que motivado pelas aventuras, pela satisfação e pela liberdade, a simples procura pelo amor é o que o instiga.

Eis, portanto, sua perfeita comparação com um Pierrot, fascinado ainda pelo amor de sua esposa, não é capaz de sair da comodidade depressiva que o assola. Busca respostas em suas próprias lembranças, lamenta-se, mas não modifica a situação em que está inserido. Um triste homem em um amor platônico pela Colombina, que já partira. A possuir eternamente uma lágrima solitária em seu rosto.
Doente de amor, este sujeito carrega sua insustentável leveza de ser, quando rapidez, instantaneidade e fluidez marcam e condicionam o homem pós-moderno. É convidado pela sociedade coletiva a provar a liberdade, os relacionamentos líquidos, escorregadios e passageiros, como se a liberdade fosse um mérito para os que seguem esta receita. Diferentemente do que a sociedade impõe, o psiquiatra ama para sempre, mesmo não sendo correspondido.

Segundo Bauman, "Amar significa estar determinado a compartilhar e fundir duas biografias, cada qual portando uma carga diferente de experiências e recordações, e cada qual seguindo seu próprio rumo" (BAUMAN, 2005, p. 69). O protagonista, entretanto, não consegue se ver independente dessa relação, e essa dependência o aprisiona e o priva do direito de liberdade que o amor verdadeiro se dispõe. Desta forma, não se liberta jamais dessa carga negativa que compromete sua existência; precisa, pois, transcender esse sentimento para algo diferente e novo.

Como seres individuais e únicos, vivendo em uma sociedade individual, onde cada sujeito é determinante de suas ações e responsáveis pelo próprio aprendizado, a angústia gerada pelo desejo da continuidade ainda é um fator de sofrimento humano. Como confirma o trecho de Erotismo, de Georges Bataille: "Somos seres descontínuos, indivíduos que isoladamente morrem numa aventura ininteligível, mas que têm a nostalgia da continuidade perdida. Suportamos mal a situação que nos amarra à individualidade que somos" (BATAILLE, 1988, p. 14).

A tarefa de ser e estar no mundo condiciona a busca pela essência universal a que todos almejam. Para os humanos, seres descontínuos, uma possibilidade de atingir a continuidade é a proximidade com a morte, esta, sempre fascinante e misteriosa. Segundo Bataille, "Se aquele que ama não pode possuir o ser amado, pensa, por vezes, em matálo, em muitos casos prefere matá-lo a perdê-lo; noutros, deseja a sua própria morte" (BATAILLE, 1988, p. 19). Para o personagem de Antunes, o desejo da continuidade através da morte, está 
inconscientemente atrelado a seu ser, quando, sem pensar profere: "Se calhar temos todos vontade de matar as pessoas de quem gostamos" (ANTUNES, 2009, p. 117).

O protagonista não deixa de amar a mulher com quem casara e em diversos momentos confidencia a si e às pessoas próximas o motivo de sua tristeza: não sabe conviver com essa rejeição, pois a ama mais que a si mesmo, reforçando toda sua complexidade de amar. Como pode ser visto no trecho ao permitir-se falar durante a terapia: "Tenho saudades de minha mulher e não sou capaz de o dizer a ela nem a mais ninguém" (ANTUNES, 2009, p. 117). E mais tarde sozinho: "Amo-te, repetia ele com voz alta agarrado ao volante como a um leme quebrado, amo-te amo-te amo-te amo-te amo-te" (ANTUNES, 2009, p. 134).

Para apresentar o ser desestabilizado que o médico se tornou, pode ser descrito o episódio em que uma gaivota bate contra o vidro de seu carro em movimento, caindo inerte no asfalto. A ave é socorrida pelo condutor do carro de trás. Neste instante, o médico repleto de culpa, não para e tampouco presta os socorros ao pássaro ferido, mesmo que tudo tenha ocorrido como uma fatalidade. No momento em que prossegue seu caminho, compara-se àquele animal: caído, debilitado, sem forças, mas ainda assim, não consegue voltar e ajudar a metáfora de si mesmo.

Para Sartre, a representação do outro é indispensável para a existência e principalmente para o autoconhecimento, "o outro é algo tão certo para nós quanto o somos nós mesmos" (SARTRE, 2010, p. 47). Colocar-se no lugar da gaivota, para o médico, era sentir a sensação contínua de estar entre a vida e a morte, embora soubesse o que lhe salvaria.

Para Bauman, em sua obra Amor líquido, "não se pode aprender a amar, tal como não se pode aprender a morrer" (BAUMAN, 2004, p. 17). Entretanto, o protagonista de Memória de elefante, viveu o amor, mas não consegue desfazer-se dele. Aprender a morrer, talvez fosse para o personagem, somente uma forma de definir seu estado, morto em vida, sem motivação que o engrene. É um psiquiatra a cuidar de muitos pacientes, incapacitado de zelar por sua condição mental.

O médico sofre o peso de ser o retornado destroçado de uma guerra. Saiu de África, mas a África não se desvencilhou de seu ser e suas recordações confundem-se com o tempo da guerra, quando, mesmo longe, ainda mantinha a família. Uma sucessão de acontecimentos perpassa sua cabeça e o aflige a todo o momento, recordações de um tempo difícil de restaurar, a não ser pelo viés da memória.

A vida em África não lhe proporcionou recordações saudáveis, seja pelos resquícios da guerra colonial, seja pela saúde debilitada em que sua filha retorna a Portugal "magra e pálida, com a cor amarelada dos brancos de Angola, ferrugenta de febre" (ANTUNES, 2009, p. 92). E o tempo em que ficara longe da família foi o mais difícil. Quando as recordações de Angola vinham à tona, "um roldão de lembranças em desordem subiu-lhe das tripas à cabeça na veemência das lágrimas contidas" (ANTUNES, 2009, p. 35). Um homem desestruturado pelas recordações em terras africanas e por toda atrocidade presenciada, não poderia continuar sua vida, incólume.

Traumatizado por essas lembranças e estilhaçado pela separação da mulher, não consegue interagir com o meio social em que vive. Não consegue seguir o próprio conselho que dá aos pacientes do hospital, manter interação saudável com outras pessoas. Fugindo de seu desespero, segue com o coração dilacerado, como os diversos corpos encontrados na guerra.

Os diálogos na trama são quase imperceptíveis, por revelar um dia inteiro de um homem incapaz de manter uma comunicabilidade entre os seus pares, tampouco com seus pacientes. Quando resolve se pronunciar, repete o mesmo discurso depressivo de todos os dias. Logo, tende a isolar-se de seus pensamentos instantâneos, procurando na agitação de bares e de ruas, um motivo para nunca estar sozinho. Mesmo diante de uma multidão, ainda sim é fruto de lágrimas adiadas, sentimentos frustrados de uma separação inesperada. 
Confuso e saudoso, vai até a escola das filhas e, de longe espreita a hora da saída, sendo observado apenas por um mendigo, que faz mal juízo desta atitude. Envergonhado e desencorajado, não se pronuncia às filhas, não se mostra, contempla apenas as recordações vivas de um tempo irrecuperável. Aliás, esconde-se, como faz em toda a narrativa, encontrando na evasão a sensação de solidão e infelicidade que o assola a todo momento.

\section{Conclusão}

Segundo Sartre "A identidade é um projeto de vida" e nessa construção o sujeito perde-se dentro de si. O protagonista é um homem insatisfeito com a vida e as mazelas que ela proporciona, não pertence sequer a si mesmo, como terá dignidade para identificar-se com alguém? Vive em um mundo desenhado por Escher ${ }^{2}$, cujas escadas o orientam a lugares distintos do desejado, ou mesmo do suposto, mas que no fim não conduzem a lugar algum. Por isso, propaga sua profunda insegurança diante do mundo e da identidade (ainda) desconhecida.

Para Maria Alzira Seixo, o médico é apenas um "indivíduo que sofre uma profunda crise de identidade, um indivíduo inadaptado, à deriva, que caindo em depressão, assiste, impotente, a sua degradação" (SEIXO, 2008, v. 1, p. 133). Enquanto não encontra seu lugar no mundo, padece sob a necessidade de resgate, um pedido incansável de sobrevivência face à vida fragmentada que vive, enclausurado em suas próprias dores.

$\mathrm{O}$ personagem médico psiquiatra atua como um alter ego do autor, que resgata, em suas vivências em África, fatos e acontecimentos reais e dolorosos, como meio de embasar uma escrita ficcional, mas completamente verossímil. Repleto de desencantos e amarguras vividos pelo protagonista, o romance Memória de elefante marca um período em que muitos autores portugueses se dedicam a uma escrita sobre o tema da colonização, sobretudo no fim da década de 70, pós-Revolução dos Cravos. Autores cuja experiência de guerra pode ser sentida e refletida pela narração de seus romances.

A crise existencial do homem passa a compor enredos de romances pós-coloniais, como ocorre com o romance de Antunes, aqui analisado. $\mathrm{O}$ narrador-personagem reflete e questiona o seu espaço, extravasa todo o peso do dia em tentativas frustradas de se desvencilhar dos pensamentos da mulher que (ainda) ama, vislumbrando sua possível existência no mundo. Vive o eterno e incompleto deslocamento como um ser que não pertence sequer a si mesmo.

A melancolia presente no romance de António Lobo Antunes reflete uma geração de soldados retornados da guerra colonial, tendo como refúgio a tentativa de apagamento desse período histórico, passando a viver sob as ruínas das lembranças de Angola. Anônimo até o final, o médico psiquiatra vive os desenganos do doloroso presente, a possibilidade de um futuro autodestrutivo e recupera, inconscientemente, através de sua "memória de elefante" o passado traumático que se quer esquecido.

\section{Referências}

ANTUNES, A. L. Memória de elefante. Rio de Janeiro: Objetiva, 2009.

ARNAUT, A. P. Entrevistas com António Lobo Antunes 1979-2007: confissões do trapeiro. Coimbra: Almedina, 2008.

BATAILlE, G. O Erotismo. Tradução: João Bénard da Costa. Lisboa: Edições Antígona, 1988.

BAUMAN, Z. Identidade. [Entrevista cedida a] Benedetto Vecchi, Zygmunt Bauman. Tradução: Carlos Alberto Medeiros. Rio de Janeiro: Jorge Zahar, 2005.

\footnotetext{
${ }^{2}$ Maurits Cornelis Escher foi um artista gráfico holandês conhecido pelas suas xilogravuras, litografias e meios-tons, que tendem a representar construções impossíveis, preenchimento regular do plano, explorações do infinito e as metamorfoses - padrões geométricos entrecruzados que se transformam gradualmente para formas completamente diferentes. CELEPAR (2021).
} 
BAUMAN, Z. O mal-estar na pós-modernidade.

Rio de Janeiro: Jorge Zahar, 1998.

BAUMAN, Z. Amor líquido. Rio de Janeiro: Jorge Zahar, 2004.

CELEPAR. Escher - Disciplina - Arte. Pr.gov. br. Disponível em: <encurtador.com.br/hLU18>. Acesso em: 10 Mar. 2021.

NEGREIROS, A. Obras completas: teatro. Lisboa: Imprensa Nacional Casa da Moeda, 1993. v. 7.

SEIXO, M. A. Dicionário da obra de António Lobo Antunes. Lisboa: Imprensa Nacional Casa da Moeda, 2008. V. 1, 2.

SARTRE, J.-P. O existencialismo é um humanismo.

Petrópolis, RJ: Vozes, 2010. 